\title{
Beyond Words: On the Experience of the Ineffable ${ }^{1}$
}

\author{
Ien Dienske \\ University of Utrecht
}

In those few moments

in the soft afternoon shine

seated amidst the silent landscape

happened the flow of my thoughts

in pure agreement

with the ineffable

which I had already known forever

and nothing in my existence remained fortuitous anymore.

(J. van Oudshoorn, 1968, p. 39)

And all we say we are saying around that which cannot be said, cannot be spoken.

(S. Griffin, 1978, p. 191)

The ineffable is inextricably connected with expression, with speaking and writing. Just as forgetfulness presupposes the existence of recollection, the inexpressible can only exist in relation to the expressible. The existence of the one is a prerequisite for the existence of the other.

Additionally, just as darkness is not the absence of light, but something which exists in itself, the ineffable is a phenomenon which really is. Those who consider evil as the absence of goodness, privatio boni, thereby deny the reality of evil. In the same way the ineffable is more than the absence and the impossibility of linguistic utterances. It is an entity, an experiential fact which manifests itself in a variety of ways. In this article a number of manifestations of the ineffable as an experience will be described.

Some examples of how the phenomenon presents itself in our daily lives will be described first. Then, after having evaluated the value of the ineffable for qualitative descriptive research, a first structural description of the phenomenon will be given. After this, examples of the ineffable as it presents itself in particular experiences will be dealt with. Here, we will restrict ourselves to what could be called "unity recovering experiences." The article concludes with a second structural description of the phenomenon.

\section{Some Appearances of the Ineffable in our Daily Lives}

You don't understand, Too-Ticki said kindly.... for the refrain deals precisely with those things which cannot be grasped. At this moment I am thinking of the northern lights. Nobody knows whether this phenomenon exists or if it is merely visible.

(From a Scandinavian children's book) 
The unnameable is connected with our bodily experiences. In this context it appears as "tacit rich knowledge." This appropriate term by Michael Murray $(1975$, p. 78$)$ will be clarified by means of an example.

When I say, "In autumn the leaves fall from the trees," a bit of tacit rich knowledge is given along with the sentence; knowledge which most of the time remains largely outside the scope of our attention. Some of this tacit rich knowledge can be voiced, made reflective. For instance, I know the smell of a moist autumn forest; I know the feel of a withered leaf and, when it is dry, how it can be ground to powder between my fingers. With my mind's eye I see how the autumn leaves change colors, and I hear them rustle over the ground, driven by the wind.

This kind of physical knowledge-four of the five senses have been mentioned in this example-silently present on the background as long as our attention is not fixed on it, can never be fully made explicit because at the same time we are always submerged in our body and cannot dissociate ourselves from it completely.

Another example. When we dance, we undergo an internal and external dancing experience. Not everything we go through while dancing can be put into words. Anybody who ever danced can verify this.

We can therefore say that the unnameable, connected with our bodily experiences, is a daily and very general manifestation of the ineffable. But there is more to it. The sentence, "In autumn the leaves fall from the trees" is comprehensible to me on the basis of my tacit rich knowledge of autumn, leaves, and trees. In the same way, a metaphor such as "the mosquitoes dance" is understandable to me because of my not fully expressible experience with dancing: it is this partly unnameable experience which allows me to use the word "dance" in its literal and figurative meaning. In short, the ineffable part of our experiences is a prerequisite for a rightful understanding of the utterances about our experiences as well as for a proper use of metaphors.

The unnameable can be present in an awkward manner when the source is a small vocabulary. Children especially suffer many difficulties caused by their small stock of words, and so do their parents, who try to understand them. A child experiencing homesickness, for instance, goes through a variety of emotions but is usually unable to say more than "I want to go home," "I've got this funny feeling in my stomach." And, on being asked, "Don't you like it here then?": "Yes, I do, but I want to go home." In this case, adults are of course aware that their protégé is homesick. But children are very glad when they themselves are able to find the words to tell their parents about these important experiences. 
This became apparent when an infant schoolteacher held a phenomenological investigation among the children at her school. ${ }^{2}$ Having been told about their teacher's own experience with homesickness, having been read a story about it, and having discussed the issue with their teacher and classmates, the children suddenly were able to tell their parents about their homesickness. On arriving home, the children began discussing the topic and almost could not stop. Experiences of days, weeks, months, sometimes over a year before were told.

The ineffable of homesickness and of desire, however, can not only be attributed to an insufficient vocabulary. Very often, emotions are complex. Desire, for instance, can be both painful and reassuring at the same time, mingled with a slight irritation against things being as they are. Or it can be softly smarting, with lovely expectations and a vague fear.

Van Oudshoorn, a novelist from the beginning of this century, gives a beautiful description of this complexity of emotions. It is an example in which happiness can no longer be distinguished from melancholy. The narrator is sitting in a covered veranda near the street with two colleagues on a sweltering Saturday evening:

It had become late. The buffet bar behind us, with all its doors and windows opened, was empty. Outside in the dark trams passed by, tightly packed with people still coming back from the surrounding country. If it grew quiet for a while, I could feel the night extending itself mildly across the rigidity of the houses to where the landscape was lying open, softly and all-enfolding, with indolent shelves of dark forests near the black water. Then the sounds of the streets re-emerged, a coolnesscarried from afar-entered the bright veranda and all that remained was just a memory of the happiness, which could not be more perfect and yet got lost in itself, like the rustling break of the sea. It is something inexpressible which befalls me in such fleeting moments. The penetrating realization of the highest plenitude of life, without actually having achieved anything of any description ... this happy experience [is] accompanied by an equally ineffable melancholy.

(van Oudshoorn, 1968, p. 36)

The narrator states that "the unison of happiness and melancholy" is "the underlying ground of this emotion." It appears to me that the author is right: together with the complexity of feelings goes the inability to convey them. Agnes Heller (1979, p. 55) expresses herself even more strongly in her study $A$ Theory of Feelings; according to her, feelings cannot be communicated concretely and totally.

Our human existence is inconceivable without desires and wishes. Our desires form a part of the temporariness of our existence. They belong to our daily lives. All of this implies that the inexpressible is always with us-not as a part of reality which still has to be explained or put into words, but as the white of an aquarelle, which intensifies the colors. 
This is precisely how the ineffable works in connection with atmosphere. In the following description-another instance from the same novel by van Oudshoorn-the reader can ascertain this:

Especially now, in this so transparent autumn atmosphere, with the faintly glowing water below the pale yellow of the broad drooping foliage, it is as a silent solemnity after the unhinging unrest of the crammed streets. Maybe that is why I took my refuge here, subconsciously.

This ineffable is inextricably connected with atmosphere. Hence, if atmosphere is the entity of life in which we move, then the ineffable of atmosphere is also present daily, usually at the background of our existence.

The unnameable also manifests itself in a way which is called forth by extreme taboos and oppression. In our western culture this is, for instance, the case when the relations between women, such as between mothers and daughters, are concerned. They are trapped in a silence which is hard to break through, precisely because of the lack of traditions in which the lives of women are told, sung, and portrayed from a woman's point of view. And without stories there is no articulation of experiences. Without stories we cannot understand ourselves and are trapped in silence (Christ, 1980, p. 1).

Elaine Showalter (1978, pp. 180-198) showed that women writers have not explored their experiences because they did not-or could not-write from their own perspective due to rigid gender-bound standards, scornful judgments, and not infrequently, open contempt from male critics. In this way women can be locked in the silence of self-imposed censorship, caused by their being subject to male censorship. This appears in the works of Susan Griffin and Adrienne Rich, ${ }^{3}$ two American authors. Griffin describes a snapshot of a mother and a daughter:

\section{Silence}

I am reminded that a great compliment of my childhood was: "She's such a quiet girl."

(Michelle Cliff, Notes on Speechlessness)

In that photograph of the child and her mother there is a wide space between them and wide space all around them, and all that space seems to be filled with silence. The child looks as if she might have cried but is not crying. Her eyes look down intently to the ground. Her hands grip the wire of a barbed-wire fence. Maybe she has just tried to say what she felt. Maybe the language did not come to her, she could not find the words. Maybe what she felt got turned in her mouth in other words. She has that look of desperation on her face, that she had tried to speak and given up. 
In the mother's body is a different kind of helplessness. She stands with one hand on her hip, another shading her eyes from the sun, looking toward her daughter. Whatever her daughter tried to say was not something she could understand. And her posture might be righteous, or even angry, if there were not a clear longing in it. As if the child's attempt to speech had touched on an old buried place in her, and so she lingers, half turned to her daughter, half turned away, knowing she will never grasp that feeling and thus already having given up, yet not able to turn from it.

And they stand there forever that way, locked in silence.

(Griffin, 1978, p. 111-112)

Extrasensory perception is another issue about which the discussion moves with great difficulty. Not only and maybe even not in the first place because of the nature of these perceptions, but especially because they are incompatible with the views of the dominant culture. It is difficult to develop a vocabulary to express oneself about these matters. We can therefore say that the unnameable as part of taboos and oppression may present itself daily, and that sometimes it is so much subject to censorship that the censored experiences may become inaccessible to language altogether.

The ineffable is emphatically present when a person wants to convey something and is unable to do so. But most of the time it remains unnoticed on the background. This is also the case with the secrets which surround us. In order to realize that these secrets exist, we have to break through the familiarity, the matter of what surrounds us. In the following quotation Susan Griffin does precisely this: she unsettles the assumption that what we cannot name cannot possibly exist. The American author states in her poetic study Woman and Nature:

Behind naming, beneath words, is something else. An existence named unnamed and unnameable. We give the grass a name and the earth a name. We say grass and earth are separate. We know this because we can pull the grass free from the earth and see its separate roots-but when the grass is free, it dies. We say the inarticulate have no souls. We say the cow's eye has no existence outside ourselves, that the red wing of a blackbird has no thought, the roe of a salmon no feeling, because we cannot name these. Yet for our own lives we grieve all that cannot be spoken, that there is no name for, repeating for ourselves the names of things which surround us what cannot be named. ... Hand and breast know each one to the other. Wood in the table knows clay in the bowl. Air knows grass knows water knows mud knows beetle knows frost knows sunlight knows the shape of the earth knows death knows not dying. And all this knowledge is in the souls of everything, behind naming, before speaking, beneath words.

(Griffin, 1978, pp. 190-191)

Susan Griffin detaches herself from the familiar interpretation of the world. When we detach ourselves from the matter of course of our common sense, of our natural and our scientific attitude towards 
the world--which is never completely possible-then wonder at the world may result.

\section{The Ineffable in Qualitative Descriptive Research}

According to Husserl, it is important that we should break through our "natural attitude" when doing phenomenological research. Husserl did not add, however, how we should change our attitudes so as to turn that which we have always taken for granted into something which is special and striking (Spiegelberg, 1982, pp. 118-123).

When focusing our attention on the ineffable, we are able to reawaken the ordinariness of our existence. In this way, we give up the routine of our rational attitude and are able to unsettle the familiarity of our world. In order to really see the world we have to detach ourselves from our familiarity with it, and only by virtue of this detachment can we learn "the unmotivated appearance of our world," according to Merleau-Ponty (1962). He also states that it is this attentive wonder which reflects best what is meant by phenomenological reduction. Noticing the ineffable helps us wonder at the world in which we live; consequently, it assists us in our execution of the phenomenological reduction. Then the awareness re-emerges that our reflective life is situated entirely within the unreflected life, and again we realize that everything verbal has its roots in the nonverbal.

In a qualitative description it will not always be possible nor necessary to react to what builds part of the picture, but which is hard to put into words. A description could become less flat, however, if attention were paid to the unnameable during the preparations. In this way, the reality of adults and children will remain more fully present in the process of analyzing and interpreting. In this way, the qualitative description of our reality is less touched up than when the attention is one-sidedly directed towards the verbalized and the expressible.

Attention for the ineffable can also aid us in developing the readiness to listen, which is of so much importance at the beginning of a qualitative analysis. After all, in a qualitative analysis we do not want to approach the research material with a rational system from the outset. Instead, we want to start by creating a space in which the tacit addresses us and in which the inexpressible can take its part.

\section{First Structural Description}

The ineffable is present daily in a number of ways. It is always there, varying with the context. It cannot be reduced to an image or object; it is not visually present. The ineffable cannot be objectified.

This is precisely the reason why it attracts our attention to the limits of our rational thought and of the instrumental rationality, directed 
towards control, effectiveness, and command. Our discursive way of thinking is powerless against the ineffable, which goes with bodily experiences, feelings, extreme taboos, and with the secrets surrounding our everyday reality. It is this powerlessness which has made the unnameable so unpopular with the Cartesian tradition in which norms and ideals of unequivocalness and transparency prevail. It interferes with these norms and ideals.

Seen from an instrumental angle, the ineffable appears as an inconvenience which still has to be put into words or which is altogether unimportant. Seen from the angle of a many-sided rationality, however, its positive value may become visible. The positive value lies in the tacit rich knowledge, the prerequisite for understanding the expressible. Here, the ineffable is enriching. This positive value is also present in enriching atmospheres, moods, and tones of the same quality. In all these cases the ineffable is unremovable.

In the case of a too small vocabulary the unnameable can be obliterated. Here, it is not enriching either: when a person is vainly searching for words, the ineffable is obtrusively present instead of unrealized and on the background, such as it usually is when one relies upon tacit rich knowledge.

When long oppression and taboos are at issue, a lot of things may become unnameable as well. Here again, it works in an impoverishing manner and can in principle be canceled. The ineffable of our feelings, our desires, and of the secrets surrounding our everyday reality, on the other hand, is unremovable. The ineffable unsettles our everyday reality when we dwell on these secrets. This may be a renewing experience.

In the Cartesian tradition there is no room for the inexpressible, which facilitates the undervaluation of the non-linguistic dimension of our lives. Yet, this dimension is not a matter of "surplus-meaning" of concepts: it is not the undefinable rest but, as we saw in the introduction, the expressible can only exist in relation to the inexpressible.

\section{The Ineffable in Unity Recovering Experiences}

The dichotomies of mind and matter, intellect and emotion, art and science, knowledge and belief, moral and rational characterize the era of the common people in Western Europe and North America. In Europe this era started around the time of the French revolution and it still continues. The crisis of the middle class inner life certainly has its roots in this multiform dualism. Agnes Heller (1979, p. 193) places the lowest point of this crisis around the twenties, since thereafter the portrayal of the middle class inner life is no longer representative in the major works of art in Europe. The epistolary novel(van Oudshoorn, 1968) from which our examples of 
unity recovering experiences will be drawn, was written between 1905 and 1922, during the lowest point of the crisis mentioned.

As we know, existentialists have paid much attention to this crisis, which we will here only characterize by means of a number of catchwords: solitude, the experience of emptiness and meaninglessness; the experience of being haphazardly present in an existence we never asked for in a world in which there is no sense of security; and, finally, the existential fear which this involves.

In the novel by van Oudshoorn, we do not exclusively encounter the characteristics of a crisis. The beginning of a solution of the crisis is also portrayed in the description of what could be called unity recovering experiences. These unity recovering experiences can only take place if there exists a unity which has been broken. This broken unity indeed exists: it was and is present in a variety of ways, not as a condition humaine but as an historical manifestation of an era which may in principle be over but which, nevertheless, continues to exist.

With these introductory remarks, the unity recovering experiences, which we will approach in a hermeneutical-phenomenological way, have been placed in a cultural context.

The contents of the epistolary novel The Ineffable, form another context which has to be known in order to be able to place the examples. The narrator is an unmarried official who moves from Holland to Berlin where, as a result of his low salary, he lives in shabby garrets. He does not make contacts easily, and therefore he is alone most of the time. He writes to his friend: "Your letters, too, I cannot dispense with. They are to me, like those of my mother, each in its own way a messenger of a good and very familiar life, from whichheaven knows why-I have been suddenly excluded" (p. 17). He feels disconnected. All of this ensures the accessibility to the heights and depths of the experiences he will be describing: experiences which alternate without him being able to control them.

The basic tones of the epistolary novel can be discerned as early as the first pages: "fleeting moments of happiness" (p. 9); "lasting depressions" (pp. 9-10); the desire for spiritual experiences which will "playfully scatter the dust of commonness"; and nostalgia for "this peculiar atmosphere" in which "everything is lively connected with each other" (p. 117). The narrator extinguishes his existential fear by refusing to feel much any longer. His general condition is a kind of "hebetation" (pp. 47, 65, 87). In this way, he is most of the time thoroughly estranged from his inner self and from the world around him. Or, to put it differently, the split between person and world is accompanied by the split of his personality. 


\section{The Other Face of Solitude}

In the unity recovering experiences described by van Oudshoorn in his epistolary novel, one can distinguish three different forms. In this article, two of these will be dealt with. The first I have called "the other face of solitude," but "a glimpse of unity" would be an equally appropriate term.

In this first type of unity recovering experience, the narrator experiences above all an echo of being connected with the life force; the connection exists for a moment and then gets lost in itself, "like the rustling break of the sea." An example of this type of experience is the description of how he is sitting in a covered veranda with his two colleagues on a sweltering Saturday evening. Below is another example in which the narrator experiences a glimpse of unity. After the "seething tidal wave" of "the sensuous," which he experiences in anonymous, commercial sex, the same peculiar mood re-emerges:

For like a seething tidal wave the sensuous has come over me and the dark realization that this impetuous urge and the intention of the committee coincided completely made the last limits fall back, expanding the evening, until the twinkling stars appeared in the shrouded, sultry sky, rays of moonlight played with the beautifully surging water and my smooth naked body reached the temporary balance with the pull of the backwash. The same deeply quieting feelings of love as when looking at grand beauty surged up from the numbness of my interior, an identical peace nestled against the objects, as if I had hurried along on a plane and was now resting on a soft slope, exhausted and yet supremely satisfied.

In reality lying stretched out on a threadbare sofa, I smoked a cigarette.

He then talks for a while with the girl, after which he further describes his experience:

The window stood ajar, the fringe of the curtain softly moved back and forth, in weak fits, vague streetnoises were carried inside and as a last echo of the so exuberant life, an atmosphere of infinity filled the shabby apartment. The same smarting sensation of delight and wistfulness, to which the purest moments of my solitude were able to lead, and more than this I therefore have not experienced.

In the period before this experience, the man was literally and figuratively impotent, cut off from the ordinary life; in this experience, however, he has become "alive" again.

He re-establishes the contact with his sexuality, with his body and with his environment. A temporary balance has originated between the beautifully surging water and his naked body, which has now been taken up in a natural undulation. At last he can rest.

In this example the ineffable is present in the orgasm (without intimacy) and in the atmosphere of infinity; the atmosphere in which 
man is directly presented with timelessness. A certain peacefulness nestles against the objects. For a moment there is no more struggle in these "purest moments of solitude" and in the wistfulness of unsatisfied desires afterwards. In this experience the recovery of unity comes so close that both an awareness of the plenitude of life and a feeling of loss emerge. It is this ambiguity which characterizes the experience. The odd atmosphere of infinity remains a smarting sensation, but the desire has been roused. After this, the man can no longer give up the search for the timelessness which penetrates time and again. This holds for the narrator as well as for the author (p. 140). From the entire passage it becomes clear that the experience has a healing influence, even if it lasts only temporarily because the narrator sees no way of integrating these experiences.

\section{The Experience of Wholeness}

A second form of the unity recovering experience is the experience of wholeness. Philosophers also have occupied themselves with this experience. The philosophical term is "metaphysical" or "ontological" experience. Both terms are foreign to the experience itself, which is to say that someone who does not know the philosophical term will not think by himself, "Look, I've had an ontological experience." This does not hold for the term "experience of wholeness."

In his book Die Ontologische Erfahrung, Karl Albert (1974) relates that the philosophers' attention for this subject mainly occurred after the Second World War (he names Germany and France) with as its climax a conference in Brussels in 1953. After this, the interest dwindled.

Karl Albert's thorough phenomenological study begins with an historical overview. In the second part he remarks in a number of places that the explicitly conscious ontological experience is the experience of the unity of all being and of the presence of all being which does not lead one to take refuge in the past nor in the future. Characteristic is the joy with which this experience is coupled. Equally typical is the fact that the experience cannot be maintained (Albert, 1974, pp. 135, 158, 160, 170). Among other things, Karl Albert wants to demonstrate that this experience is of all times and, in principle, of all humans. Because all of this needs an example, we will now return to the narrator of The Ineffable who writes letters from Berlin to his friend.

The Berlin letterwriter has relapsed "to an utter inability to cope with life" and the "fortuity" of his existence has become a "waste of chilliness and withering." No wonder then that he was "greatly struck ... to discover for a while this deep feeling of love still kept intact": 
Thoughtlessly I had wandered into a deserted park, until somewhere from between the foliage the perspective of the open landscape with a road framed with trees loomed up from the soft haze, as from a long oblivion.

The petty solace of my interior enlarged itself to the resigned grandeur of this world, sending through me a timidly joyful thrill. After years, I felt myself of life again, being lovingly taken in, so that originally I did not know what was happening to me.

But, once seated below a big tree, in the centre of the silent landscape, the enchantment still lasted, the new warmth pouring into the emptiness and dissatisfaction of my heart and I rested after the severe hardship in the tenderest embrace, all bitterness and weariness falling from me; the unnameable becoming more softly accessible than the plain reality ever was. How happy have I felt in these fleeting moods and how perfectly created for this other life, which was approaching me in such a peculiar manner. For this is the highest and the most incredible, that despite everything and out of its own accord life was bending over to me-as a mother over her wayward child-and in this fostering, loving warmth I felt a shrine of truth break. In those few moments, seated amidst the silent landscape in the soft afternoon sunshine, happened the flow of my thoughts, in pure agreement with the ineffable, which I had already known forever and nothing in my existence remained fortuitous anymore.

(pp. 88-89)

\section{The Experience of Wholeness as a Way of Knowing}

An experience itself is irreducible reality. The experience when voiced represents the original, but never equals it. In social scientific work we can, among others, work with our own direct experience, our voiced experience and with the experience of other people. We know that not every experience is voiced appropriately. This does not hold for the experiences described by van Oudshoorn. He masterfully puts into words experiences which are hard to convey. This experience of wholeness is recognizable; there is no reason to be skeptical or mistrusting towards this description. We will take the description as it stands.

The passage reads that the unknowable becomes accessible and that a shrine of truth breaks. If we take this seriously, this experience is a way of knowing. It is a way of knowing which expands and'reunites person and world: "My interior enlarged itself to the resigned grandeur of this world." It is a participatory way of knowing in which there is no distance between subject and object: "to partake of life again." There exists between person and world an intimacy, characteristic for this way of knowing: the closeness of the silent landscape which surrounds him, the closeness of his expanding interior, and the closeness of the unknowable which becomes accessible. It is a way of knowing which apparently has a healing influence since new warmth pours into the emptiness of his heart, all bitterness vanishes, and he can rest. This way of knowing is restful. 
The narrator himself is receptive; his body is once again the entrance to his surroundings and the landscape is open as well. In the experience of wholeness there is openness, and one way or the other truth is experienced as well. The atmosphere of being haphazardly present in an existence he never asked for, a haphazardness he calls "a waste of chilliness and withering," is overcome. Nothing is fortuitous anymore: in the experience of wholeness the man experiences his existence as meaningful. When the world and one's own existence are meaningful again, then there is coherence as well, a coherence which had been lost due to active dualism.

The narrator names a dichotomy which he surpasses in this experience: his thoughts and the ineffable, which cannot be approached by means of rational thought, are in pure agreement. For the duration of this experience, the gulf between emotion and intellect has been bridged. It is a joyful experience-"How happy have I felt"-which is moving and which satisfies desires. The atmosphere of infinity is also present in this quotation, especially in the first sentence. In this way, timelessness becomes knowable through this experience.

\section{Atmosphere, Mood, and Attitude}

Accurately, the given fragment evokes an atmosphere which characterizes the experience of wholeness. The ineffable is always incorporated in an atmosphere and mood, but in connection with the unity recovering experiences, the Berlin letterwriter often explicitly mentions atmosphere and mood:

to acknowledge this peculiar atmosphere, in which everything is lively connected with each other.

an atmosphere which inspired both body and mind with youthful buoyancy.

the moods, which brought light and movement in my seclusion.

again, the same atmosphere of a full and forceful life rose in me.

In the mood in which the narrator finds himself there is silence, subtlety, and softness. There also is an emotion which is timid and joyful. "Thoughtlessly I had wandered into the deserted park"; this is how the fragment starts. Thoughtlessly-not bent on something tangible; not brooding or reasoning-only then, it seems, there is room for something else. Only in this state is the narrator taken off his guard by life itself, expressing itself in the open landscape. Only in this way could a mood in which intimacy and the unknowable are present be created. This mood, then, goes together with an attitude of openness for the described experience. Heidegger has strongly emphasized this "openness" and "receptibility." He stresses the im- 
portance of a mood which diametrically opposes the attitudes of the ideal Western human being: a man, full of initiative and willpower, acting systematically and effectively. Heidegger stresses the importance of an attitude which is considered "feminine." He mentions diffidence (Scheu) and the ability to wait until life itself addresses you (Zuspruch des Seins). The initiative is not ours: one cannot produce an experience of being-or experience of wholeness-by willfully trying to create one. This is also made clear in the fragment "being lovingly taken in" and "this other life, which was approaching me in such a peculiar manner."

If the initiative is not ours then, in order to have this experience, one needs an entirely different attitude and, along with it, a completely different affective condition from a one-sidedly "male" attitude. The mood and attitude needed, therefore, require a rehabilitation of "the feminine" as a symbol.

The intensity, the vividness, and the abundance of the unity recovering experiences are inexpressible although poets and writers have always been able to evoke them with words. As long as we do not talk about it, it does not seem hard to find the words. Wasn't it all very clear during the experience itself? But once we start talking about it, the experience falls apart. This is another reason why I feel respect for the descriptions in the novel at issue; descriptions in which some of the original splendor and mood have been preserved.

When they are not integrated, the experiences may fade, and one starts to doubt whether they were real at all. The Berlin letterwriter states:

At present, when writing about it, all of this seems to me so little and so vague, however, that again I have to doubt if I have given you even the faintest notion of it in my letters.

In the next letter he stresses again:

I do not know if I have expressed myself clearly enough, and even then, if the said amounts to more than a game of words only. Myself, I can feel all this only vaguely. Sometimes as a shadow of truth.

The fullness of the experience is inexpressible, and its recollection is vulnerable in that it may fade and become unreal.

In the first sentence of the quoted fragment it is stated that the perspective of the open landscape loomed before him as from a long oblivion. He remembers it from long ago. The sight and the atmosphere form a remembrance which slowly returns to him. Retrospectively, he has always known that it existed. 
These paraphrased formulations of the Berlin letterwriter tally with the statements of the aforementioned Karl Albert in Die Ontologische Erfahrung that there is a positive, marked experience of being. In a clearly conscious ontological experience people often know that it is not something completely foreign to them. We know the experience in an undefined way: still folded up, as it were, and yet retrospectively recognizable. This is why Karl Albert mentions the primacy of this experience: in every experience the ontological experience is enclosed from the beginning (Albert, 1974, p. 186).

Apart from this, we can say that the ineffable as a source of joy and fulfillment is vaguely familiar to us. We recognize it retrospectively in the direct, explicit experience of wholeness. This ineffability par excellence will not be taken into account although gifted writers may remind us of what we actually have already known forever.

\section{Second Structural Description}

The internal structure of the ineffable as experience consists of a relatively constant basic structure and a varying structure of meaning. This structure of meaning contains both the experienced meaning of the person who describes his experience and the effect of the phenomenon on adults and/or children. No phenomenon exists in a vacuum, however, but in a number of external relations of the phenomenon. We therefore do not only get to know a phenomenon by means of a clarification of its internal structure, but also by relating it to more comprehensive contexts.

The basic structure consists of the generality of the ineffable. After all, it is inextricably connected with the language of adults and children. A second constituent of the basic structure is the impossibility to objectify the ineffable. It is impossible to portray it by means of an image or object. Furthermore, there is the factor of constancy. The ineffable is always present in our lives in a variety of ways; for instance, in our bodily experiences or also in atmosphere, the entity of life in which we move. Finally, the fundamentality should be remarked upon. If language is one of the constituent characteristics of our human existence, then the same holds for the ineffable.

In order to trace the structure of meaning we have examined some examples of the unnameable in our daily lives. In the removable manifestations of the phenomenon, the unnameable is impoverishing. If it is unremovable, however, it may be either impoverishing-as in the event of severe bodily pain or fear-or enriching - as in the tacit rich knowledge, in atmosphere, or in joyful moods. Both the removable and the unremovable forms of the ineffable may be obtrusively present, they may remain in the background, or they may even be pre-reflective.

Apart from this, the unnameable may have another specific effect. If we allow its existence to penetrate our consciousness, then it can un- 
settle the ordinariness of our lives in a renewing and refreshing manner. From all this it becomes clear that the basic structure is more constant than the structure of meaning.

Another illustration of the variability of the structure of meaning is given when we consider the ineffable in particular experiences. When taking a closer look at the unity recovering experiences, the structure of the ineffable partly resembles the experience of it in our daily lives. In the first experience mentioned, the unnameable is unremovable and enriching: the full richness of this experience cannot be imparted, and the experience itself, evoked in words, is probably only understandable for those who know what it is about. The ineffable is obtrusively present in the discussion of this kind of experience since words always fall short of expressing what is really meant.

Despite these similarities, there are three issues in the structure of meaning of unity recovering experiences which do not occur in the examples from our daily lives. First of all, the inexpressible exists in the timelessness which is directly experienced in an atmosphere of infinity. Secondly, the ineffable is present in the healing influence of the experience as a whole even if this influence is only temporary, i.e., when the experience is not integrated. The healing influence is evoked in the experienced openness, intimacy, and rest; in transcending dualisms; in a direct and enfolding meaningfulness; and in an inexpressible joy. Finally, the experience of truth is more explicitly and more comprehensively present in the inexpressible of particular experiences than it is in the unnameable in our daily lives.

We also perceive the ineffable and its importance for people in the external relations in which cultural/historical meanings of the ineffable will be illustrated. In the first place, the unnameable will be connected with instrumental rationality and furthermore with the aforementioned active dualism.

Instrumental rationality is directed towards regulation, effectivity, and control. It is what Heidegger calls "the calculating thought." Instrumental rationality involves the use of clear-cut notions, counting, and measuring. The ineffable, which turns out to be an important phenomenon in our lives, indicates the limits and the restrictions of the instrumental rationality. Against this fundamental, common, and important phenomenon, instrumental rationality is powerless. The ineffable affects the core of the Cartesian ideals of unequivocalness and transparency. If the unnameable is always present in our lives, inextricably connected with languages, then these ideals are not only unattainable, but they also distort the human reality. The exaggerated emphasis on power, not only in "male society," but also in many subjects of conversation within the women's movement, is an extension of the dominant and one-sided, 
instrumental-rationalistic perspective (regulation, command, effectivity, control). The ineffable is a correction on this onesidedness.

In the Western sciences dualism functioned very strongly. Emotions, values, art, ethics, and religion, all of these were considered taboo or "philosophical" and were consequently banned from scientific discourse. Full emphasis was laid on discursive, objective thought and on a restricted view of "empirical." If the active dualism is being overcome more and more in the sciences, then surely the ineffable will be rehabilitated as well.

The unnameable reminds us of a rich, uncontrollable dimension of our existence and of the importance of the nonlinguistic. "In the beginning was not the Word-earlier reigned the grand silence" is the first line of a poem, written by a Dutch poet, J. C. Schagen, who will have the final say in this article:

in the beginning

was not the Word-earlier

Reigned the grand silence

before the first word

is the sigh of the sea

and after the last

it lies in the dust

you can pick it up like that

the first word-nothing

it lies in the dust

you can pick it up like this

the last word-nothing

\section{Notes}

1. This paper was presented at the International Human Science Research Conference, Faculty of Education, University of Alberta, Edmonton, Alberta, on May 21-25, 1985.

2. The investigation was carried out by Ingrid Valk in 1982.

3. See for instance the title of a collection of lectures by Adrienne Rich, On Lies, Secrets and Silence, London: Virago, 1980, or consider the poem "Mother-in-law" in the collection, A wild patience has taken me this far, New York: Norton and Company, 1981.

\section{References}

Albert, K. (1974). Die ontologische erfahrung. Raingen: A. Hennverlag.

Christ, C. P. (1980). Diving deep and surfacing: Women writers on spiritual quest. Boston: Beacon Press.

Griffin, S. (1978). Woman and nature: The roaring inside her. New York: Harper and Row. 
Heller, A. (1979). A theory of feelings. Assen: Van Gorcum.

Merleau-Ponty, M. (1962). Preface. In Phenomenology and perception. London: Routledge and Kegan Paul.

Murray, M. (1975). Modern critical theory: A phenomenological introduction. The Hague: M. Nijhoff.

Showalter, E. C. (1978). Halfjaarlijks tijdschrift voor literatuur en kunst. Amsterdam: Deltos, Elsevier, $\mathrm{nr} 1$.

Spiegelberg, H. (1982). The phenomenological movement (third revised and enlarged edition). The Hague: $M$. Nijhoff.

van Doosselaera, E. (1975). Angst en gelatenheid als openheid voor het Zijnsmisterie. Tijdschrift voor Filosofie, 37, 454-456.

van Oudshoorn, J. (1968). Het onuitsprekelijke. Amsterdam: Van Oorschot. van Schagen, J. C. (1971). Ik ga maar en ben. Amsterdam: Van Oorschot. 